\title{
Chlorinated Long-chain Fatty Acids. Their Properties and Reactions. VIII. The Kinetics and Stereochemistry of the Alkaline Dehydrochlorination of Diastereoisomeric
} Sodium 9,10-Dichlorooctadecanoates

\author{
KALEVI PIHLAJA* and MARTTI KETOLA
}

Department of Chemistry, University of Turku, SF-20500 Turku 50, Finland

The base-promoted removal of the first chlorine of sodium erythro-9,10-dichlorooctadecanoate in aqueous ethylene glycol was found to produce sodium 9(10)-chloro-cis-octadecenoate. The corresponding threo isomer gave 9(10)-chlorotrans-9-octadecenoate by a 2.5 times higher rate $(363 \mathrm{~K})$ in identical circumstances.

When kept in aqueous alkaline ethylene glycol (5.4 wt. \% of water) at $418 \mathrm{~K}$ threodichloride lost all of its chlorine within $24 \mathrm{~h}$, whereas erythro-dichloride lost only $68 \%$ of its chlorine content within $825 \mathrm{~h}$ in agreement with the fact that intermediate vinylic cismonochlorides react much slower than the corresponding trans-monochlorides.

Stereochemically the first reaction step is a trans-elimination process in which the different reaction rates of the diastereoisomers were shown to be mainly due to the differences in the ground state energies of their reactive conformations $\left[k_{\text {threo }} / k_{\text {erythro }}=\mathbf{5 . 0}\right.$ (obs.) and 6.5 (calc.) at $298 \mathrm{~K}]$.

Diastereoisomeric compounds, such as threoand erythro-isomers, may have different reaction rates. 1 For example, the base-promoted dehydrochlorinations of sodium threo- and erythro-9(10)-chloro-10(9)-hydroxyoctadecanoates have been found to occur at different rates. ${ }^{2}$

The kinetics and mechanisms of the removal of $\mathrm{HCl}$ from sodium threo-9,10-dichlorooctadecanoate have been studied earlier., ${ }^{3,4}$ To complete these studies and to clarify the stereochemical course of the reaction, sodium erythro-9,10-dichlorooctadecanoate (1) was also prepared and subjected to alkaline dehydrochlorination.

Acta Chem. Scand. B 28 (1974) No. 10

\section{EXPERIMENTAL}

GLC analyses were carried out on a Perkin Elmer F 11 gas chromatograph equipped with a hydrogen flame ionization detector. The stainless steel columns were packed with Chromosorb G (60/80 mesh) coated with a polar (5\% XE-60, $200 \mathrm{~cm} \times 3 \mathrm{~mm}$ ) or nonpolar silicone grease (3\% SE-30, $300 \mathrm{~cm} \times$ $3 \mathrm{~mm})$. The chromatograms were run under isothermal conditions at $160{ }^{\circ} \mathrm{C}$ with the former column and at $210{ }^{\circ} \mathrm{C}$ with the latter. Before analyses the acids were esterified with diazomethane in diethyl ether containing $10 \%$ of methanol $(\mathrm{v} / \mathrm{v})$. The methyl esters of stearic (C18), arachidic (C20), 9-octadecynoic (C18) and 9(10)-chloro-trans-9-octadecenoic acids were used as reference compounds.

Proton resonance spectra were recorded on a Perkin Elmer R10 spectrometer (60 MHz) using $\mathrm{CCl}_{4}$ as solvent and tetramethyl silane (TMS) as internal reference. The sample concentrations varied from 5 to $10 \%(w / w)$. A Perkin Elmer Model 180 spectrophotometer was used to record IR absorption spectra using a thin film of sample between $\mathrm{KBr}$ windows. UV absorption spectra were run on a Unicam SP 800 spectrophotometer using absolute ethanol (the State Alcohol Monopoly, Grade AaS, for Spectrophotometry) as solvent. Mass spectra of the prepared methyl esters of the acids were determined with GLC-MS $[0.9 \mathrm{~m} \times 3$ $\mathrm{mm}$ stainless steel column filled with silicone oil OV-17 (2\%; on Chromosorb G 60/80 mesh; $220{ }^{\circ} \mathrm{C}$ ) connected to a Perkin Elmer M 270 mass spectrometer (ionizing potential $70 \mathrm{eV}$ )].

The chlorine contents of erythro-9,10-dichlorooctadecanoic acid and its dehydrochlorination products were determined by the method described previously. ${ }^{5}$ 
Kinetic measurements and calculation of the reaction rate coefficients were accomplished as shown earlier. ${ }^{3,4}$

Syntheses. Elaidic acid was prepared by isomerization of oleic acid (Fluka AG, $96 \%$ by GLC) by nitrogen oxide. ${ }^{6}$ Its melting point after consecutive recrystallizations from diethyl ether and acetone at $-17{ }^{\circ} \mathrm{C}$ was $42.5{ }^{\circ} \mathrm{C}$ (lit. ${ }^{6} 43-44{ }^{\circ} \mathrm{C}$ ).

erythro-9,10-Dichlorooctadecanoic acid was obtained by chlorination of elaidic acid (12 g) in $\mathrm{CCl}_{4}$ solution $(150 \mathrm{ml})$ saturated with chlorine. ${ }^{5}$ After evaporation of solvent and excess chlorine the oily residue was treated with urea $(12 \mathrm{~g})$ in $100 \mathrm{ml}$ of chloroform containing $10 \mathrm{ml}$ of methanol to remove saturated acids present as impurities in the starting material. The mixture was stirred at $22{ }^{\circ} \mathrm{C}$ for $44 \mathrm{~h}$. The excess urea and its fatty acid complexes were then filtered off. Recrystallization of the crude dichloride (about $17 \mathrm{~g}$, after removal of solvent) twice from hexane (4 $\mathrm{g}$ of acid per $1 \mathrm{ml}$ of solvent) at $-17^{\circ} \mathrm{C}$ yielded $7.2 \mathrm{~g}$ of acid, m.p. $44.5-45.5^{\circ} \mathrm{C}$ (lit. ${ }^{7} 47.5^{\circ} \mathrm{C}$ ). The chlorine content based on six determinations was $20.39 \pm 0.11 \%$ (calc. $20.07 \%$ ). ${ }^{1} \mathrm{H}$ NMR $\left(\mathrm{CCl}_{4}\right): \delta 0.89\left(\mathrm{CH}_{3}-\right), 1.33\left[-\left(\mathrm{CH}_{2}\right)_{n}-\right]$, $2.22-2.31\left(-\mathrm{CH}_{2} \mathrm{COOH}\right), 1.86\left(-\mathrm{CH}_{2} \mathrm{CHCl}-\right)$, $3.9[-\mathrm{CH}(\mathrm{Cl})-]$, and $12.1(\mathrm{COOH})$. IR, $v_{\max }$ $1710(\mathrm{COOH})$ and $646 \mathrm{~cm}^{-1}(\mathrm{C}-\mathrm{Cl})$. The acid was converted to its sodium salt (1) by methanolic alkali.

Separation of the reaction products. The products formed in the first dehydrochlorination step were obtained by keeping a sample of sodium erythro-9,10-dichlorooctadecanoate (1) in aqueous alkaline ethylene glycol at $110^{\circ} \mathrm{C}$ for $100 \mathrm{~min}$. For the further removal of $\mathrm{HCl}$ from the vinylic monochloride formed from 1 more drastic conditions were used: the reaction vessel was kept at $145^{\circ} \mathrm{C}$ for 343 and $825 \mathrm{~h}$. The reaction mixture included $1.5 \mathrm{~g}$ of 1 and $0.3 \mathrm{~mol}$ of $\mathrm{NaOH}$ in $400 \mathrm{~g}$ of ethylene glycol, which contained $5.4 \%$ of water by weight. The dehydrochlorination products were separated from the reaction mixtures by extraction with $\mathrm{CCl}_{4}$ as described in an earlier paper. ${ }^{8}$ The amount of the viscous residues was about $1 \mathrm{~g}$ in each case.

\section{RESULTS AND DISCUSSION}

Analyses of the reaction products. After esterification with diazomethane the dehydrochlorination products of 1 separated from the reaction mixtures were analyzed by GLC, NMR, IR, UV, and mass spectroscopy.

The product, after the first dehydrochlorination step, contained $10.1 \%$ of chlorine $(10.0 \%$ in theory). IR $v_{\max }: 3030 \quad(\mathrm{CH}=), \quad 1710$ $(\mathrm{COOH}), \mathrm{I} 650(\mathrm{CH}=\mathrm{CCl})$ and $650 \mathrm{~cm}^{-1}(\mathrm{C}-\mathrm{Cl})$,

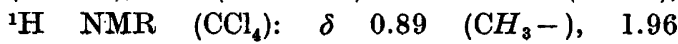

$\left(-\mathrm{CH}_{2} \mathrm{CH}=\right), 2.08\left(-\mathrm{CH}_{2} \mathrm{CCl}=\right.$ or $\left.-\mathrm{CH}_{2} \mathrm{C}=\right)$, and 5.51 ( $-\mathrm{CH}=\mathrm{CCl}-$; a triplet; $J=7.5 \mathrm{~Hz}$ ). The weak signal at about $\delta 3.6$ may be due to $-\mathrm{CH}(\mathrm{OR})$-, where $\mathrm{R}$ may be $\mathrm{H}$ or the anion of ethylene glycol, or to the alkoxy protons of $-\mathrm{CH}\left(\mathrm{OCH}_{2} \mathrm{CH}_{2} \mathrm{OH}\right)=\mathrm{CH}-$. These systems may be formed through the addition of water or ethylene glycol to a double or triple bond. The UV spectrum of the first-step product had a maximum at $218 \mathrm{~nm}$ and an inflexion at $232 \mathrm{~nm}$, which may be due to the formation of some conjugated dienes.

Because of the low reactivity of vinylic chloride formed in the first dehydrochlorination step of 1 the removal of the second mol of $\mathrm{HCl}$ required more vigorous reaction conditions: a sample of 1 was treated with alkaline reagent for 343 and $825 \mathrm{~h}$ at $145{ }^{\circ} \mathrm{C}$. The dehydrochlorination products separated contained 8.3 and $6.4 \%$ of chlorine, respectively. The IR spectrum of the product obtained after the shorter dehydrochlorination period had a new band at $1960 \mathrm{~cm}^{-1} \quad(\mathrm{C}=\mathrm{C}=\mathrm{C})$, which is weakened by the prolonged alkali treatment. The product after $825 \mathrm{~h}$ showed also a weak IR band at $2280 \mathrm{~cm}^{-1}(\mathrm{C} \equiv \mathrm{C})$. The presence of the allene group is confirmed by a multiplet at $\delta 5.0$ in the NMR spectra of the dehydrochlorination products separated after 343 and $825 \mathrm{~h}$. The product after $343 \mathrm{~h}$ had UV maxima at 228 and $255 \mathrm{~nm}$, but after $825 \mathrm{~h}$, only at $255 \mathrm{~nm}$.

The GLC data relative to methyl stearate for the 'methylated' dehydrochlorination products of 1 are collected in Table 1. The results show, that on the polar XE-60 column, the main component (peak 2) of the first dehydrochlorination product is eluted after methyl 9(10)-chloro-trans-9-octadecenoate (peak 11). On the non-polar SE-30 column these compounds (peaks 2 and 11) have similar relative retention times. These results are in accordance with those of Stein ${ }^{9}$ and Gunstone ${ }^{10}$ for the corresponding bromo derivatives, methyl 9(10)-bromo-cis-9- and 9(10)-bromo-trans-9. octadecenoates. The mass spectrum of peak 2 showed the parent peak $\left(\mathrm{M}^{+}\right)$at $m / e 331$ in agreement with the molecular weight (330.9) of $\mathrm{C}_{19} \mathrm{H}_{35} \mathrm{O}_{2} \mathrm{Cl}$ and the fragment peaks at $m / e 299,294$, and 263, probably due to $\left[\mathrm{M}-\mathrm{CH}_{3} \mathrm{OH}\right]^{+},[\mathrm{M}-\mathrm{HCl}]+$, and $\left[\mathrm{M}-\mathrm{CH}_{3} \mathrm{OH}-\right.$ $\mathrm{HCl}]^{+}$, respectively. Thus the principal product 
Table 1. Gas chromatographic retention data for some model compounds and for dehydrochlorination products of sodium erythro-9,10. dichlorooctadecanoate (1). Retention times are given relative to the retention times for methyl stearate $[1.00 \equiv 5.24 \mathrm{~min}(\mathrm{XE}-60)$ and $1.00 \equiv$ $6.5 \min (\mathrm{SE}-30)]$.

\begin{tabular}{lll}
\hline Peak & Compound & Relative re- \\
No. & & tention times \\
& & XE-60 SE-30
\end{tabular}

Methyl esters of the dehydrochlorination products $110^{\circ} \mathrm{C} ; 100 \mathrm{~min}$

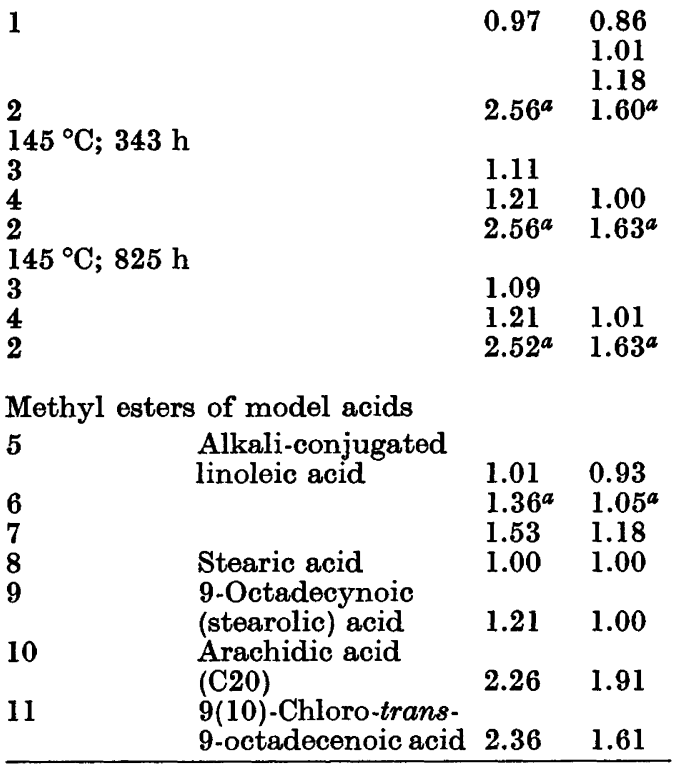

a The major peak in the chromatogram.

in the first dehydrochlorination step seems to be sodium 9(10)-chloro-cis-9-octadecenoate.

Two compounds formed after the further dehydrochlorination (peaks 3 and 4 in Table 1) gave the molecular ion peaks at $m / e 294$ indicating the presence of dienic, allenic, or ynoic esters with the molecular weight (294.4) of $\mathrm{C}_{19} \mathrm{H}_{34} \mathrm{O}_{2}$. According to the GLC data peak 4 may be an acetylenic ester since its relative retention time on the XE-60 column is equal to that of an authentic sample of methyl 9octadecynoate (peak 9). Gunstone et al. ${ }^{10}$ observed that on a polar column the longchain allenic $\mathrm{C}_{18}$-ester was eluted before the corresponding acetylenic one. Thus the relative retention times 1.1 (peak 3) and 1.2 (peak 4) may also indicate that the former is an allenic intermediate. Moreover, after $343 \mathrm{~h}$ the area of the peak of the allenic ester (peak 3 in Table 1) was larger than that of the ynoic ester (peak 4), while after the dehydrochlorination for $825 \mathrm{~h}$, the order was reversed.

GLC and UV spectroscopy pointed out that the first-step dehydrochlorination product contained only small amounts of conjugated dienes, which moreover, were not among the products formed during the further dehydrochlorination of 1 . In the latter case the equilibrium reached was in favour of allenes and acetylenes, but not of conjugated dienes (Scheme 1).

Kinetics and mechanisms of dehydrochlorina. tion. The values of the rate coefficients at five temperatures are collected in Table 2 and the values of thermodynamic functions of activation obtained from them by the method of least squares, in Table 3. Accordingly, the first chlorine from sodium erythro-9,10-dichlorooctadecanoate (1) is removed as $\mathrm{HCl}$ rather easily, although the rate of this reaction is about 2.5 times higher for the corresponding threo isomer under identical conditions (Table 3). This observation is in accordance with that reported by Gunstone et al. ${ }^{10}$ for the corresponding dibromooctadecanoates. The removal of $\mathrm{HCl}$ from the vinylic cis-monochloride under the conditions used was too slow for determination. By heating of 1 with alkali for $825 \mathrm{~h}$ at $145^{\circ} \mathrm{C} 36 \%$ of the second chlorine was reacted,

Table 2. Rate coefficients for the first dehydrochlorination step of sodium erythro-9,10dichlorooctadecanoate in aqueous alkaline ethylene glycol $\left(x_{\mathrm{H}_{2} \mathrm{O}}=0.165\right)$ at different temperatures. ${ }^{a}$

\begin{tabular}{lll}
\hline $\begin{array}{l}\text { Tempera- } \\
\text { ture } \\
{ }^{\circ} \mathrm{C}\end{array}$ & $10^{5} k$ & $10^{5} k_{\mathrm{OH}}$ \\
& $\left(\mathrm{s}^{-1}\right)$ & $\left(\mathrm{kg} \mathrm{mol}^{-1} \mathrm{~s}^{-1}\right)$ \\
\hline 80 & $7.02 \pm 0.09^{b}$ & $4.54 \pm 0.06^{b}$ \\
90 & $20.5 \pm 0.3$ & $13.3 \pm 0.2$ \\
90 & $19.9 \pm 0.3$ & $12.9 \pm 0.2$ \\
95 & $32.4 \pm 0.3$ & $20.5 \pm 0.2$ \\
100 & $51.0 \pm 0.6$ & $33.0 \pm 0.4$ \\
100 & $48.0 \pm 0.6$ & $31.1 \pm 0.4$ \\
\hline
\end{tabular}

$a$ The substrate concentration was $0.01 \mathrm{~mol}$ per $\mathrm{kg}$ of solvent, sodium hydroxide concentration was $0.773 \mathrm{~mol}$ per $\mathrm{kg}$ of solvent. ${ }^{b}$ Standard deviation.

Acta Chem. Scand. B 28 (1974) No. 10 
Table 3. Values of the thermodynamic functions of activation and relative rates at $90{ }^{\circ} \mathrm{C}$ for the alkaline dehydrochlorination of sodium threo-and erythro-9,10-dichlorooctadecanoates in aqueous alkaline ethylene glycol containing $16.5 \mathrm{~mol} \%$ of water.

\begin{tabular}{|c|c|c|c|c|c|}
\hline & $\begin{array}{l}\text { Reaction } \\
\text { step }\end{array}$ & $\begin{array}{l}\Delta H \neq \\
\mathrm{kJ} \mathrm{mol}^{-1}\end{array}$ & $\begin{array}{l}\Delta S \neq \\
\mathrm{J}^{\mathrm{mol}^{-1}} \mathrm{~K}^{-1}\end{array}$ & $\begin{array}{l}\Delta G \neq \\
\mathrm{kJ} \mathrm{mol}^{-1}\end{array}$ & Rel. rate \\
\hline erythro & I & $103.2 \pm 2.4^{a}$ & $-36.9 \pm 6.6^{a}$ & $116.6 \pm 0.05^{a}$ & 140 \\
\hline threo ${ }^{b}$ & $\begin{array}{l}\text { I } \\
\text { II }\end{array}$ & $\begin{array}{r}93.8 \pm 0.4 \\
108.1 \pm 1.8\end{array}$ & $\begin{array}{l}-55.3 \pm 1.2 \\
-64.3 \pm 4.3\end{array}$ & $\begin{array}{l}113.9 \pm 0.02 \\
131.5 \pm 0.2\end{array}$ & $\begin{array}{r}340 \\
1 \\
\end{array}$ \\
\hline
\end{tabular}

a Standard deviation. ${ }^{b}$ Refs. 3, 4 .

whereas from threo-9,10-dichlorooctadecanoate all chlorines were removed after $24 \mathrm{~h}$ at $145^{\circ} \mathrm{C}$. This result confirms that the dehydrochlorination of 1 also occurs through trans(anti)elimination (E2) where 9(10)-chloro-cis-9-octadecenoate is the first step product. The difficulty of the further dehydrochlorination of this cis-monochloro-ene (2) is mainly due to the great steric hindrance for the cis-(syn). elimination.

According to Staley and Doherty ${ }^{11}$ the formation of allene from 4-bromo-cis-4-octene is very much faster than that of the triple bond through cis(syn)-elimination. Their results show also that trans(anti)-elimination of $\mathrm{HBr}$ from 4-bromo-trans-4-octene yields the triple bond about forty times faster than the corresponding cis-isomer forms the allene. Thus the rates of dehydrobromination of monobromooctenes decrease in the sequence $k_{\text {anti }}>k_{\text {allene }}>k_{\text {syn }}$. Vigorous treatment of 1 with alkali yielded acetylenic and allenic intermediates but very little, or no conjugated dienes in accordance with the above results and those of Gunstone

$$
\begin{aligned}
& \mathrm{R}^{1}-\mathrm{CHCl}-\mathrm{CHCl}-\mathrm{R}^{2} \\
& \mathrm{OH}^{-} \downarrow-\mathrm{HCl}
\end{aligned}
$$

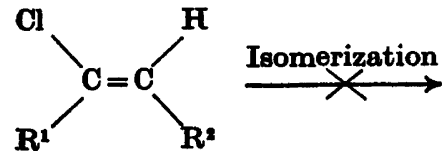<smiles>[R]/C=C(\[R1])Cl</smiles>

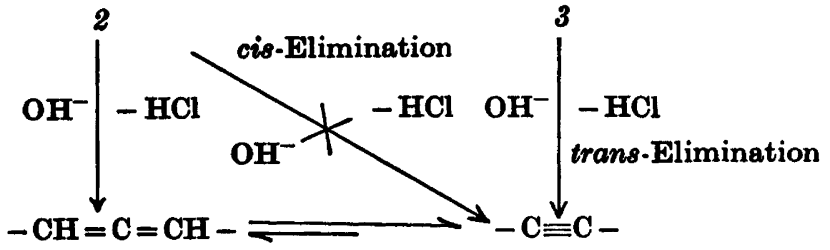

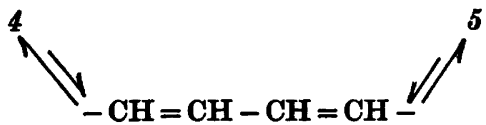

6

$\mathrm{R}^{1}=\mathrm{CH}_{3}\left(\mathrm{CH}_{2}\right)_{7}-$

$\mathrm{R}^{2}=-\left(\mathrm{CH}_{2}\right)_{7} \mathrm{COONa}$

Scheme 1. The possible reaction pathways in the alkaline dehydrochlorination of 1 .

Acta Chem. Scand. B 28 (1974) No. 10 
threo

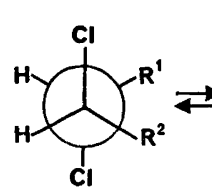

A<smiles>[R]C1C2CC3(Cl)C(Cl)C(Cl)C1C3C2[R]</smiles>

$\mathbf{B}$

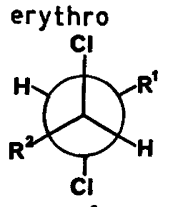

$A^{\prime}$

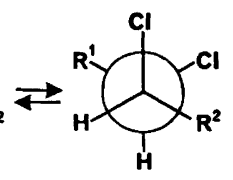

C
Fig. 1. The minimum energy conformations of sodium threo-(A-C) and erythro-9,10-dichlorooctadecanoates $\left(\mathrm{A}^{\prime}-\mathrm{C}^{\prime}\right)$.

et $a .^{10}$ for the corresponding bromo octadecanoates. Consequently, the base-promoted dehydrochlorination of 1 may be proposed to occur through the following steps (Scheme 1): in the first reaction step trans(anti)-elimination produces 9(10)-chloro-cis-9-octadecenoate (2) which during prolonged dehydrochlorination gives allenic intermediates $(4)$ and octadecynoates (5) both of which are in equilibrium with dienic derivatives $(6)$. The formation of 5 through cis(syn)-elimination or through isomerisation of 2 to trans-chloro-ene (3) followed by trans (anti)-elimination is only of minor importance. Secondary isomerizations of 4 and 5 may, of course, give other allenic and acetylenic derivatives, ${ }^{12,13}$ which may also be formed from the vinylic cis-chloro alkene 2 (Scheme 1) through elimination of $\mathrm{HCl}$ preceded by a double bond shift.

Stereochemistry of the first dehydrochlorination step. The basepromoted dehydrochlorination proceeds under the conditions used by E2 mechanism. ${ }^{14}$ A stereochemical requirement for this mechanism is that the leaving groups $\mathrm{H}$ and $\mathrm{Cl}$ are in an anti (or trans) periplanar conformation..$^{3,4,14,15}$

Both sodium threo- and sodium erythro-9,10dichlorooctadecanoates have three minimum energy conformations (Fig. 1) from which only $\mathrm{C}$ (threo isomer) and $\mathrm{B}^{\prime}$ and $\mathrm{C}^{\prime}$ (erythro isomer) can undergo the E2 elimination.

The rate of a given reaction of a conformationally heterogeneous system may be presented by the relation ${ }^{15}$ $k=\sum x_{i} k_{i}$

where $x_{i}$ is the mol fraction and $k_{i}$ the rate coefficient of the reaction studied for the $i$ th conformation. Hence the total rates for the first dehydrochlorination steps of sodium threo $\left(k_{t}\right)$ and erythro-9,10-dichlorooctadecanoates $\left(k_{e}\right)$ may be written

$k_{t}=k_{\mathrm{A}} x_{\mathrm{A}}+k_{\mathrm{B}} x_{\mathrm{B}}+k_{\mathrm{C}} x_{\mathrm{C}}$

$k_{e}=k_{\mathrm{A}^{\prime}} x_{\mathrm{A}^{\prime}}+k_{\mathrm{B}^{\prime}} x_{\mathrm{B}^{\prime}}+k_{\mathrm{C}^{\prime}} x_{\mathrm{C}^{\prime}}$

If the dehydrochlorination reaction occurs predominantly as an anti-elimination $k_{\mathrm{C}} \gg k_{\mathrm{A}} \approx k_{\mathrm{B}} \approx 0$ and $k_{\mathrm{C}^{\prime}} \approx k_{\mathrm{B}^{\prime}} \gg k_{\mathrm{A}^{\prime}} \approx 0$. Accordingly,

$k_{t} \approx k_{\mathrm{C}} x_{\mathrm{C}}$ and

$k_{e}=k_{\mathrm{B}^{\prime}} x_{\mathrm{B}^{\prime}}+k_{\mathrm{C}^{\prime}} x_{\mathrm{C}^{\prime}}$

Moreover, it is reasonable to assume that $k_{\mathrm{C}}=2 k_{\mathrm{B}^{\prime}}=2 k_{\mathrm{C}^{\prime}}$ and $x_{\mathrm{B}^{\prime}}=x_{\mathrm{C}^{\prime}}$ where the factor two is due to the double anti-arrangement of the conformation C. ${ }^{14}$ Consequently,

$k_{t} / k_{e}=x_{\mathrm{C}} / x_{\mathrm{C}^{\prime}}$

If the gauche interactions due to the groupings $R^{1}$ and $R^{2}$ do not differ essentially from those of a methyl group the mol fraction of the different conformations may be estimated using the following values (in $\mathrm{kJ} \mathrm{mol}{ }^{-1}$ ) for the various gauche interactions at $298 \mathrm{~K}: \mathrm{R}^{1}-\mathrm{R}^{2}$ $(\mathrm{Me}-\mathrm{Me})^{16}+2.7, \mathrm{Cl}-\mathrm{Cl}^{17}+5.0$, and $\mathrm{R}^{1}-\mathrm{Cl}$ or $\mathrm{R}^{2}-\mathrm{Cl}(\mathrm{Me}-\mathrm{Cl})^{17}-0.2$.

The estimated interaction energies for the conformations of threo- and erythro-9,10-dichlorooctadecanoates are then (Fig. 1)

$$
\begin{array}{lll}
\mathrm{A}+2.3 & \mathrm{~B}+7.7 & \mathrm{C}+4.6 \\
\mathrm{~A}^{\prime}-0.4 & \mathrm{~B}^{\prime}+7.5 & \mathrm{C}^{\prime}+7.5
\end{array}
$$

Since ${ }^{15} x_{i} / x_{i+1}=\exp \left[\left(H_{i}-H_{i+1}\right) / R T\right] \quad$ and $\sum x_{i}=1$ we can estimate that $x_{\mathrm{C}} \simeq 0.26$ and $x_{\mathrm{C}^{\prime}}=0.04$ and thus $k_{\mathrm{t}} / k_{\mathrm{e}} \simeq x_{\mathrm{C}} / x_{\mathrm{C}^{\prime}} \simeq 6.5$ at $298 \mathrm{~K}$. Experimentally, the rate ratio for the threoand erythro-9,10-dichlorooctadecanoates was found to be 2.5 at $363 \mathrm{~K}$ and 5.0 at $298 \mathrm{~K}^{14}$

The calculated and experimental results being very close to each other support the postulation that the reaction is really preponderantly trans-elimination (E2) and that the difference in the reaction rates is mainly due to the different ground state energies of the reactive conformations of the threo and erythro isomers. 
Acknowledgements. The financial aid obtained by the Finnish Academy, the Division of Technical Sciences, is gratefully acknowledged. Thanks are also due to Mrs. Maija-Liisa Nissi for technical and to Miss Joyce Addison (University of Stirling, Scotland) for secretarial assistance.

\section{REFERENCES}

1. Eliel, E. L. Stereochemistry of Carbon Compounds, McGraw, New York, San Francisco, Toronto and London 1962, p. 137.

2. Ketola, M. Acta Chem. Scand. 27 (1973) 1328.

3. Ketola, M. and Pihlaja, K. Suom. Kemistilehti $B 43$ (1970) 289.

4. Ketola, M. and Pihlaja, K. J. Amer. Oil Chem. Soc. 48 (1971) 462.

5. Pihlaja, K. and Ketola, M. Suom. Kemisti. lehti $B 43$ (1970) 21.

6. Teeter, H. M., Gast, L. E., Raleigh, D. and Woods, L. C. J. Amer. Chem. Soc. 73 (1951) 2302.

7. King, G. J. Chem. Soc. (1949) 1817.

8. Ketola, M. Tetrahedron 30 (1974) 2717.

9. Stein, R. A. J. Amer. Oil Chem. 38 (1961) 636.

10. Gunstone, F. D. and Hornby, G. M. Chem. Phys. Lipids 3 (1969) 91.

11. Staley, S. W. and Doherty, R. F. Chem. Commun. (1969) 288.

12. Fischer, H. In Patai, S. The Chemistry of Alkenes, Interscience, London, New York and Sydney 1964, Vol. 1, p. 1060.

13. Mavrov, M. V. and Kucherov, V. F. In Kazanskii, B. A., Knunyants, I. L., Shemyakin, M. M. and Melnikov, N. N. Organic Compounds: Reactions and Methods, JFI/Plenum, New York, Washington and London 1973, Vol. 21, p. 95.

14. Ketola, M., Chlorinated Long-chain Fatty Acids, their Synthesis, and the Kinetics and Mechanisms of the Basepromoted Dehydrochlorination of their Sodium Salts, Ph. D. Thesis, University of Turku, Turku 1973.

15. Eliel, E. L., Allinger, N. L., Angyal, S. J. and Morrison, G. A. Conformational Analysis, Interscience, New York 1965.

16. Pihlaja, K. and Taskinen, E. Some Thermochemical Applications to Heterocyclic Chemistry. In Katritzky, A., Ed., Physical Methods in Heterocyclic Chemistry, Academic, New York 1974 Vol. VI.

17. Abraham, R. J. and Parry, K. J. Chem. Soc. $B(1970) 539$.

Received May 13, 1974. 